\title{
Brunei Publications in the Science Citation Index Expanded (1973-2016): Bibliometrics and comparison with other tropical countries
}

\author{
Yuh-Shan $\mathrm{Ho}^{1 *}$, Linda Biaw Leng $\operatorname{Lim}^{2}$ \& Julián Monge-Nájera ${ }^{3}$ \\ 1. Trend Research Centre, Asia University, Taichung 41354, Taiwan; ysho@asia.edu.tw \\ 2. Chemical Sciences, Faculty of Science, Universiti Brunei Darussalam, Jalan Tungku Link, Gadong, Negara Brunei \\ Darussalam, Brunei; linda.lim@ubd.edu.bn \\ 3. Laboratorio de Ecología Urbana, Vicerrectoría de Investigación, Universidad Estatal a Distancia, 2050 San José, Costa \\ Rica; julianmonge@gmail.com \\ * Correspondence
}

Received 24-IV-2018. C Corrected 30-V-2018. Accepted 29-VI-2018.

\begin{abstract}
Brunei is a small tropical country -located in Southeast Asia- for which there are no previous bibliometric studies. Here we analyze papers published by Brunei scientists from 1973 to 2016 in the Science Citation Index Expanded and compare results with other tropical countries. We identified 1547 publications and 11 document types. The most productive categories were ecology, multidisciplinary geosciences, inorganic and nuclear chemistry, and environmental sciences. Singapore Medical Journal published most of these papers, and the three most productive institutions were Universiti Brunei Darussalam, RIPAS Hospital, and Universiti Teknologi Brunei. UK and Malaysia were the most frequent collaborating countries. M.A. Ali from the Universiti Brunei Darussalam was the most prolific author and a Brunei independent article written by C.K. Morley from the Universiti Brunei Darussalam in 2002 had the highest number of citations of the whole period and the highest number in 2016. The tropical countries of Central America and Asia have a few similarities but also important differences, and both are highly heterogeneous in scientific organization and productivity. Rev. Biol. Trop. 66(3): 1090-1100. Epub 2018 September 01.
\end{abstract}

Key words: tropical country; publication type; scientific collaboration; scientific productivity; research areas.

In recent years there has been an increasing number of analyses about the scientific publications of tropical countries, for example, Costa Rica (Monge-Nájera \& Ho, 2012), Panama (Monge-Nájera \& Ho, 2015), Nicaragua (Monge-Nájera \& Ho, 2017a), Honduras (Monge-Nájera \& Ho, 2017b), and El Salvador (Monge-Nájera \& Ho, 2017c). In these studies, trends of articles and citations per publication by year (Chuang, Olaiya, \& Ho, 2012), citations per publication and country's number of articles by type of collaboration and authorship (Chuang \& Ho, 2015), and percentage of publications and number of journals in each Web of Science category (Monge-Nájera \& Ho, 2017b) found a general increase in quantity and quality over the years. However, there are fewer studies along the same line for the Asian tropics (Payumo \& Sutton, 2015).

Negara Brunei Darussalam, the Abode of Peace, is a tropical country in Borneo Island, South East Asia. It consists of four main districts: Brunei-Muara, Tutong, Belait and Temburong, of which the latter is separated from the other three by Limbang, a district in the Sarawak state of East Malaysia. The country's main Gross domestic product (GDP) comes from crude oil and natural gas. The population of Brunei Darussalam is less than half a million, and the people are given free medical and education services, and do not pay taxes. Previously a British protectorate state, Brunei Darussalam gained its Independence in 1984. The official language is Malay, but other 
languages such as English and Chinese are widely spoken.

In this study, we analyse Brunei publications in the SCI-EXPANDED as follows: document type, language of publication, publication year, collaboration pattern, journal and Web of Science category, and highly cited articles.

\section{MATERIALS AND METHODS}

We used the Science Citation Index Expanded (SCI-EXPANDED), the Web of Science Core Collection, and Clarivate Analytics. We searched for documents with the word "Brunei" in the address field and found 1590 documents, published between 1900 and 2016 (Date of search: August 04, 2017). Results were refined by countries/territories with "Brunei” (Monge-Nájera \& Ho, 2015). Documents with the word "Brunei" but not actually from Brunei -for example Univ Brunei Darussalam, Malaysia; Univ Brunei, Tanzania; and Brunei Shell Petr Co, Malaysia- are not included. In total, 1547 documents were finally found as valid publications by authors from Brunei. We reclassified articles from England, Scotland, Northern Ireland, and Wales as "United Kingdom" (UK). Articles from Hong Kong before 1997 were reclassified as being from China (Chuang, Wang, \& Ho, 2011).

Web of Science Core Collection citations can change over time and cannot be easily compared; to solve this limitation, Ho's group proposed a new indicator, $T C_{\text {year }}$ (Chuang et al., 2011; Wang, Fu, \& Ho, 2011), i.e. total citations from publication to the end of the most recent year (or last year), for example 2016 in this study $\left(T C_{2016}\right)$. Citations per publication $\left(C P P_{2016}\right)$ is $T C_{2016} /$ number of publications (TP) (Ho \& Ho, 2015). In addition, $C_{2016}$, the total citations only in 2016, was also applied (Ho, 2012). The advantage of $T C_{\text {year }}$ and $C_{\text {year }}$ is that they are invariable and ensure repeatability compared with the index of citation from the Web of Science Core Collection $(\mathrm{Fu}$, Wang, \& Ho, 2012). It was also pointed out that it is not appropriate to use a single indicator to evaluate the impact of an article (Ho \& Hartley,
2016). Researchers should pay more attention to the top articles with $C_{\text {year }}$ but not to those with $T C_{\text {year }}$ only, because some highly cited articles with $T C_{\text {year }}$ have not had a high impact in recent years (Ho \& Hartley, 2016). In 2004, a particular analysis of document types and their citations per publication was proposed by Hsieh, Chiu, Lee, and Ho (2004) and we follow it here.

\section{RESULTS}

Document type and language of publication: A total of 1547 publications with at least one author from Brunei in the SCIEXPANDED was found within 11 document types indexed in the Web of Science. The most used document type was article $(81 \%$ of 1547 publications) followed distantly by the letters $(6.2 \%)$ and meeting abstracts (5.9\%) (Table 1). Reviews had twice as many citations per publication $\left(C P P_{2016}\right)$ than proceeding papers, articles, and notes. A review entitled "Dolomite: Occurrence, evolution and economically important associations" (Warren, 2000) from the Universiti Brunei Darussalam was not only the most frequently cited review with $T C_{2016}$ of 343 but also the most frequently cited paper of any kind from Brunei. Number of authors per publication, $A P P$, was also about double for reviews than for book chapters and articles. However, an article entitled "Mortality of emergency abdominal surgery in high-, middle- and low-income countries" (Bhangu et al., 2016) had the most authors (an extraordinary number: 1480 authors). Of all document types, only articles were used for further analysis because they included whole research ideas and results (Ho, Satoh, \& Lin, 2010). Language of publication is one of basic concerns in bibliometric studies as a big data analysis (Wang \& Ho, 2011); in Brunei, all 1257 articles were published in English.

Publication year: In recent years, a relationship between number of articles and their citations $\left(C P P_{\text {year }}=T C_{\text {year }} / T P\right)$ by decade (Ho, 2012) and year (Chuang et al., 2012; Chuang 
TABLE 1

Citations and authors according to document type

\begin{tabular}{lcccccc}
\multicolumn{1}{c}{ Document type } & $T P$ & $\%$ & $A U$ & $A P P$ & $T C_{2016}$ & $C P P_{2016}$ \\
Article & 1,257 & 81 & 7,545 & 6.0 & 13,583 & 11 \\
Letter & 96 & 6.2 & 170 & 1.8 & 96 & 1.0 \\
Meeting abstract & 91 & 5.9 & 487 & 5.4 & 5 & 0.055 \\
Review & 64 & 4.1 & 878 & 14 & 1555 & 24 \\
Proceedings paper & 47 & 3.0 & 145 & 3.1 & 569 & 12 \\
Editorial material & 23 & 1.5 & 58 & 2.5 & 22 & 1.0 \\
Correction & 10 & 0.65 & 41 & 4.1 & 2 & 0.20 \\
Note & 4 & 0.26 & 10 & 2.5 & 41 & 10 \\
Book chapter & 1 & 0.065 & 7 & 7.0 & 3 & 3.0 \\
Book review & 1 & 0.065 & 1 & 1.0 & 0 & 0 \\
Discussion & 1 & 0.065 & 1 & 1.0 & 1 & 1.0
\end{tabular}

$T P$ : number of articles; $A U$ : number of authors; $A P P$ : number of authors per publication $(A U / T P) ; T C_{2016}$ : total citations since publication to the end of 2016; $C P P_{2016}$ citations per paper $\left(T C_{2016} / T P\right)$.

\& Ho, 2015) was proposed as a figure. It has been applied for publication trends in countries in the tropics, for example Panama (MongeNájera \& Ho, 2015), Nicaragua (Monge-Nájera \& Ho, 2017a), Honduras (Monge-Nájera \& Ho, 2017b), El Salvador (Monge-Nájera \&
Ho, 2017c), Cameroon (Tchuifon Tchuifon, $\mathrm{Fu}, \& \mathrm{Ho}, 2017$ ), and India (Elango \& Ho, 2017). Figure 1 shows the distribution of the 1 257 articles from Brunei over years and their citations per publication $\left(C P P_{2016}=T C_{2016} /\right.$ $T P)$. From 1973 to 1991, there were less than

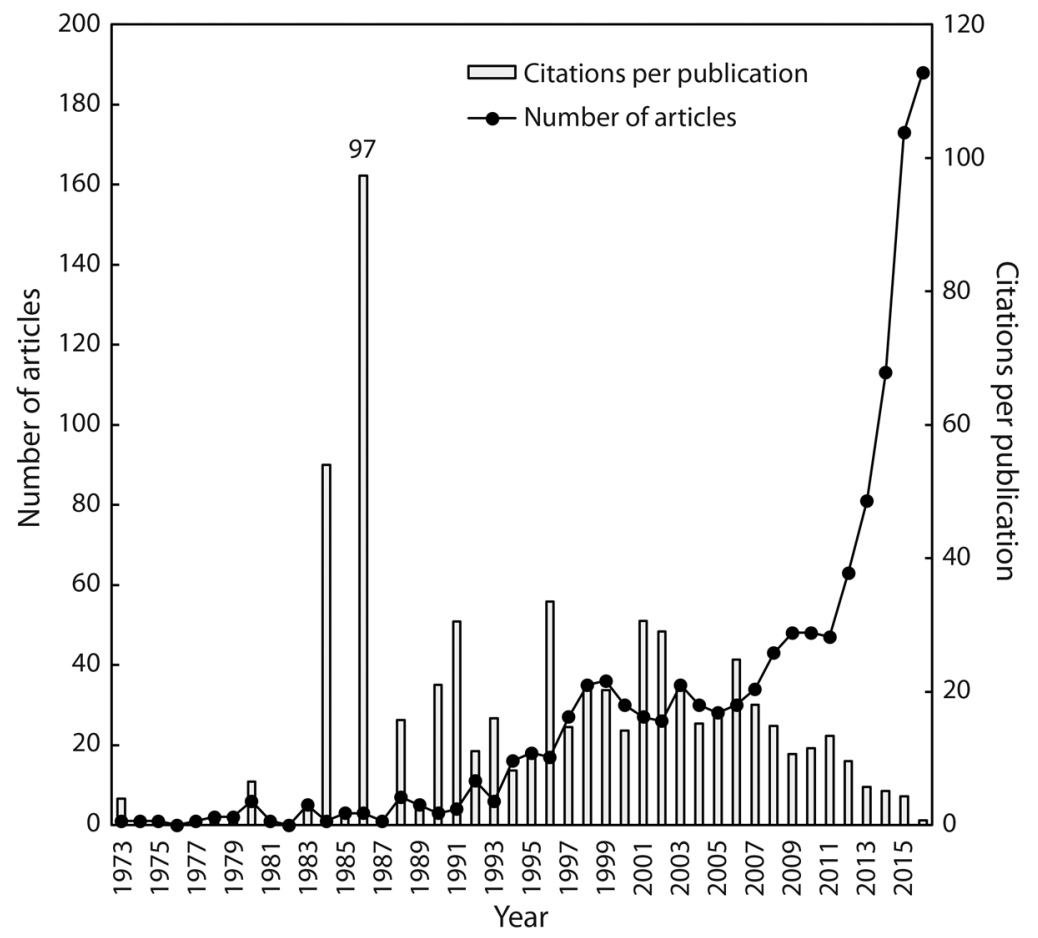

Fig. 1. Trends of articles and citations per publication from 1973 to 2016. 
TABLE 2

20 most collaborative countries

\begin{tabular}{lcccccc}
\multicolumn{1}{c}{ Country } & $T P$ & $T P R(\%)$ & $F P R(\%)$ & $R P R(\%)$ & $T C_{2016}$ & $C P P_{2016}$ \\
UK & 160 & $1(13)$ & $2(5.3)$ & $2(5.7)$ & 2,074 & 13 \\
Malaysia & 159 & $2(13)$ & $1(7.5)$ & $1(7.3)$ & 1,472 & 9.3 \\
Australia & 143 & $3(11)$ & $4(3.5)$ & $3(3.6)$ & 1,738 & 12 \\
USA & 133 & $4(11)$ & $6(3.2)$ & $5(3.3)$ & 2,673 & 20 \\
Singapore & 93 & $5(7.4)$ & $5(3.3)$ & $6(3.1)$ & 727 & 7.8 \\
China & 91 & $6(7.2)$ & $3(4.3)$ & $3(3.6)$ & 916 & 10 \\
Germany & 72 & $7(5.7)$ & $8(1.4)$ & $8(1.5)$ & 908 & 13 \\
India & 54 & $8(4.3)$ & $12(1.0)$ & $16(0.65)$ & 409 & 7.6 \\
Bangladesh & 50 & $9(4.0)$ & $16(0.72)$ & $16(0.65)$ & 750 & 15 \\
France & 44 & $10(3.5)$ & $10(1.2)$ & $9(1.1)$ & 896 & 20 \\
Japan & 43 & $11(3.4)$ & $11(1.1)$ & $11(1.1)$ & 833 & 19 \\
Canada & $12(3.3)$ & $13(1.0)$ & $12(0.81)$ & 892 & 22 \\
Sri Lanka & 41 & $13(3.2)$ & $13(1.0)$ & $12(0.81)$ & 347 & 8.7 \\
South Korea & 40 & $14(3.1)$ & $7(2.1)$ & $7(1.7)$ & 309 & 7.9 \\
Taiwan & 39 & $15(2.8)$ & $9(1.4)$ & $9(1.1)$ & 275 & 7.9 \\
Switzerland & 35 & $16(2.1)$ & $16(0.72)$ & $12(0.81)$ & 284 & 11 \\
Thailand & 26 & $16(2.1)$ & $24(0.32)$ & $24(0.32)$ & 610 & 23 \\
South Africa & 26 & $18(1.9)$ & $19(0.56)$ & $19(0.57)$ & 453 & 19 \\
Pakistan & 24 & $19(1.8)$ & $28(0.24)$ & $24(0.32)$ & 132 & 5.7 \\
Saudi Arabia & 23 & $19(1.8)$ & $33(0.16)$ & $28(0.24)$ & 232 & 10
\end{tabular}

$T P$ : number of collaborative articles with Brunei; $F P$ : first-author articles; $R P$ : corresponding-author articles; $R$ : rank; $T C_{2016}$ : total citations since publication to the end of 2016; $C P P_{2016}$ citations per paper $\left(T C_{2016} / T P\right)$.

10 articles per year, and then there were 11 articles in 1992; this was followed by a slightly fluctuating increase and a sharp increase 2010.

In 1986 only three articles had $C P P_{2016}$ higher than 97, which can be attributed to the article "Fault geometries in basementinduced wrench faulting under different initial stress states" (Naylor, Mandl, \& Sijpesteijn, 1986) by authors from Oman, Netherlands, and Brunei, respectively, with a $T C_{2016}$ of 291. Similarly, only one article, "Paleomagnetism of the sveconorwegian mobile belt of the fennoscandian shield" (Stearn \& Piper, 1984) had a high $C P P_{2016}$ of 54. The earliest Brunei article in SCI-EXPANDED was "Minimum phase criterion of sampled signals" published in IEEE Transactions on Geoscience and Remote Sensing in 1973 (Berkhout, 1973) with a $T C_{2016}$ of 4 .

Collaboration: to evaluate the impact of publication type, Ho's group proposed a relationship between publication type and citations per publication $\left(C P P_{\text {year }}\right)$ (Chuang \& Ho, 2015). It has recently been applied in tropical countries such as Nicaragua (Monge-Nájera \& Ho, 2017a), Honduras (Monge-Nájera \& Ho, 2017b), and El Salvador (Monge-Nájera \& Ho, 2017c). Types included TP (total publications), $N F R$ (both first and corresponding-authors are not from the country), $N R$ (correspondingauthor is not from the country), $N F$ (first-author is not from the country), IC (internationally collaborative publications), $N C$ (nationally collaborative publications), II (institutional independent publications), $C I$ (country independent publications), $F P$ (publications with first-author in the country), $R P$ (publications with corresponding-author in the country), and FR (both first and corresponding-authors are from the country) (Chuang \& Ho, 2015; Monge-Nájera \& Ho, 2017a, 2017b; Elango \& Ho, 2017). Internationally collaborative articles (IC) received higher $C P P_{2016}$ than those with 
local institutional collaboration and those in which the corresponding author was from Brunei (Chuang \& Ho, 2015).

A total of 160 articles were done in collaboration with UK institutions, and 159 articles were based on collaborative efforts with Malaysia (followed by Australia and the USA) (Table 2). Malaysia has had more leading role in collaborative relationships: $7.5 \%$ of all articles had a first-author affiliated with a Malaysia institution (7.3\% of 1236 articles with corresponding information). International collaboration with Thailand had the highest $C P P_{2016}$ (23). Canada, France and the USA also had high $C P P_{2016}$ values $(22,20$, and 20, respectively). On the other hand, international collaboration with Pakistan had the lowest $C P P_{2016}$ (5.7) followed by India, Singapore, Taiwan, and South Korea (Fig. 2).
Leading institutions and authors: there were some institutions with identical names and misspellings in the Web of Science database (Elango \& Ho, 2017). Data from institutes that have changed names were grouped together under the new name. For instance, articles from Univ Brunei Darussalam, Univ Brunei, UBD, and Univ Brunei Darussalam Jalan Tungku Link, were grouped under Universiti Brunei Darussalam (UBD). In total, $26 \%$ were single institution articles and $74 \%$ were interinstitution collaborative articles, including 1.9 $\%$ nationally collaborative articles and $72 \%$ internationally collaborative articles. It is not surprising to have such low percentage of nationally collaboration in Brunei because the country has only few institutions. Universiti Brunei Darussalam published $70 \%$ of 1257 Brunei articles as it was the first university in

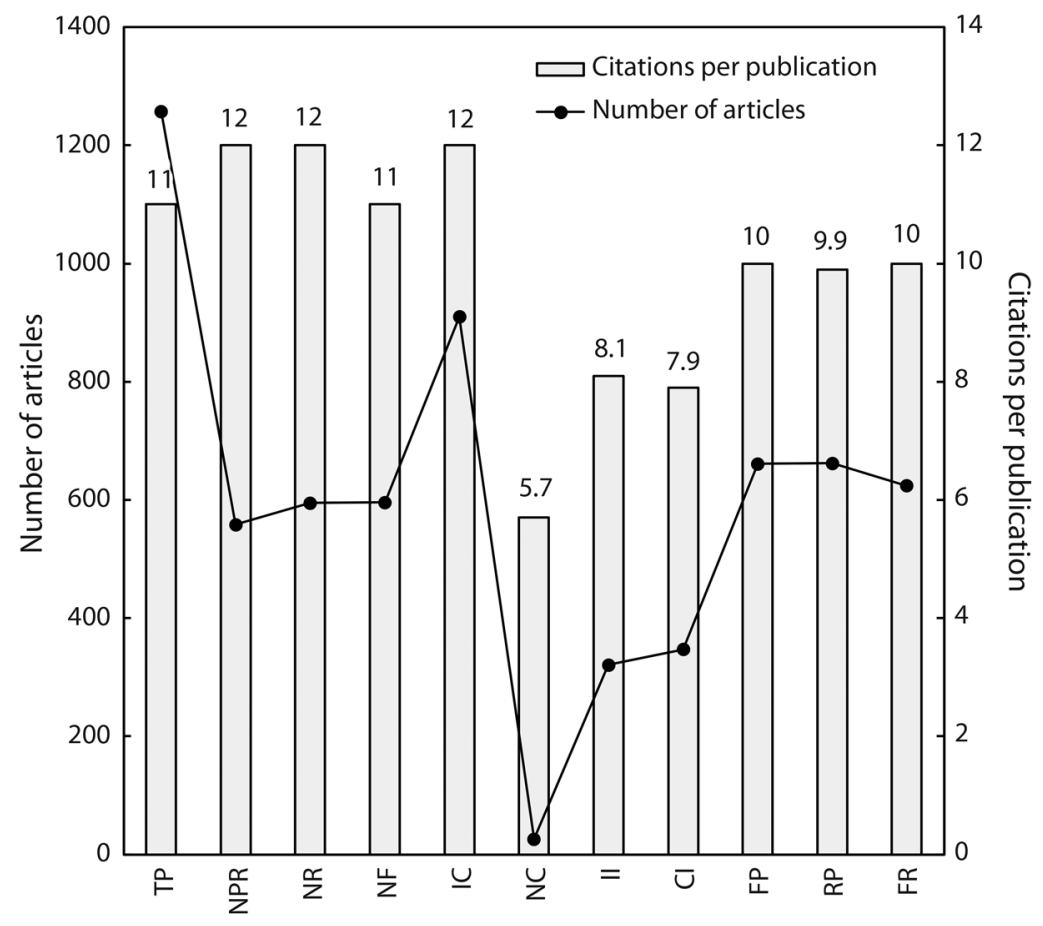

Fig. 2. Citations per publication and number of articles by type of collaboration and authorship. TP: total articles; NFR: both first and corresponding-authors are not from Brunei; $N R$ : corresponding-author is not from Brunei; $N F$ : first-author is not from Brunei; $I C$ : internationally collaborative publications; $N C$ : nationally collaborative publications; $I I$ : institutional independent publications; $C I$ : Brunei independent publications; FP: first-author is from Brunei; $R P$ : corresponding-author is from Brunei; FR: both first and corresponding-authors are from Brunei. 
Brunei. The university also published the most single institutional articles (175 articles; 54 $\%$ of 323 single institutional articles); interinstitutional articles ( $75 \%$ of 934 inter-institutional articles); first-author articles (37\% of 1 257 first-author articles); corresponding-author articles (36\% of 1236 corresponding-author articles); and single-author articles (63\% of 167 single-author articles).

Both the RIPAS hospital and the Universiti Teknologi Brunei (UTB) published the same number of articles (139 articles each). The RIPAS hospital ranked second on single institutional articles (23\%), first-author articles $(7.1 \%)$, and corresponding-author articles $(7.2 \%)$ while the Universiti Teknologi Brunei ranked second on inter-institutional articles (13 $\%)$ and single-author articles (10\%). Other institutions published less articles, including Brunei Shell Petroleum Co. Sendirian Berhad (35 articles), Ministry of Health (15), Jerudong Park Medical Centre (12), High Commission of India (9), Department of Agriculture (8), Sultan Saiful Rijal Technical College (8), and Suri Seri Hospital (6).

Of 12 authors with 20 or more articles, nine were from Universiti Brunei Darussalam, two from RIPAS hospital, and one from Universiti Teknologi Brunei (Table 3). It is generally accepted that the first-author actually made the greatest contribution, and should receive a greater proportion of the credit (Riesenberg \& Lundberg, 1990). Convention among the experimental sciences suggests that the most important authorship positions are the first and the last, who often include the correspondingauthor (Costas \& Bordons, 2011). M.A. Ali, from the Universiti Brunei Darussalam, was the most productive author with 54 Brunei articles including 41 first-author articles and 42 corresponding-author articles, followed by V.H. Chong from the RIPAS hospital with 52 articles, who was also ranked $1^{\text {st }}$ on corresponding-author articles. W. Roth from Universiti Brunei Darussalam published 13 articles including 12 single-author articles ranked top in Brunei. In addition, A.H. Mirza from the Universiti Brunei Darussalam and P.U. Telisinghe from the RIPAS hospital published only two first-author articles and no any corresponding-author and single-author articles.

\section{Journal and Web of Science category:} In this context, 1257 Brunei articles were published in 712 journals across 157 Web of Science categories in SCI-EXPANDED. Among these, $70 \%$ of 712 journals contained only one Brunei article; $16 \%$ contained two, and

TABLE 3

Top 12 authors published at least 20 articles in Brunei

\begin{tabular}{llcccc}
\multicolumn{1}{c}{ Author } & \multicolumn{1}{c}{ Institution } & $R(T P)$ & $R(F P)$ & $R(R P)$ & $R(S P)$ \\
M. A. Ali & Universiti Brunei Darussalam & $1(54)$ & $1(41)$ & $1(42)$ & N/A \\
V. H. Chong & RIPAS hospital & $2(52)$ & $2(29)$ & $1(42)$ & $7(5)$ \\
J. N. Sahu & Universiti Teknologi Brunei & $3(47)$ & $106(1)$ & $10(12)$ & N/A \\
H. Mirza & Universiti Brunei Darussalam & $4(42)$ & $66(2)$ & N/A & N/A \\
L. B. L. Lim & Universiti Brunei Darussalam & $5(33)$ & $13(9)$ & $4(15)$ & N/A \\
D. J. Marshall & Universiti Brunei Darussalam & $5(33)$ & $9(11)$ & $8(13)$ & $29(1)$ \\
T. U. Grafe & Universiti Brunei Darussalam & $7(30)$ & $17(7)$ & $18(8)$ & N/A \\
B. K. Morley & Universiti Brunei Darussalam & $8(29)$ & $4(15)$ & $4(15)$ & $4(7)$ \\
P. U. Telisinghe & RIPAS hospital & $9(23)$ & $66(2)$ & N/A & N/A \\
V. D. Didenko & Universiti Brunei Darussalam & $10(21)$ & $3(21)$ & $3(19)$ & $10(4)$ \\
P. Becker & Universiti Brunei Darussalam & $11(20)$ & $6(12)$ & $8(13)$ & $15(3)$ \\
R. Ramasamy & Universiti Brunei Darussalam & $11(20)$ & $41(3)$ & $12(11)$ & N/A
\end{tabular}

$R$ : rank; TP: number of articles; $F P$ : first-author articles; $R P$ : corresponding-author articles; SP: single-author articles; N/A: not available. 
$6.9 \%$ contained three Brunei articles. A total of 1178 articles were published in 662 journals with impact factor information in 2016, $I F_{2016}$, and 79 articles were published in 50 journals without $I F_{2016}$.

Brunei published the most articles in Singapore Medical Journal $\left(I F_{2016}=0.667\right)$ with 36 articles, followed by Polyhedron ( $I F_{2016}$ $=1.926)$ with 24 , Biotropica $\left(I F_{2016}=1.730\right)$ with 15, Transition Metal Chemistry $\left(I_{2016}=\right.$ $1.358)$ with 14 , Zootaxa $\left(I F_{2016}=0.972\right)$ with 13 , Desalination and Water Treatment $\left(I_{2016}=\right.$ $1.631)$ with 12, PLoS One $\left(I F_{2016}=2.806\right)$ with 12 , and Marine and Petroleum Geology $\left(I_{2016}\right.$ $=2.888)$ with 10 . Lancet $\left(I F_{2016}=47.831\right)$ with only one article, entitled "Hyperkalaemia in a Thai man" (Smit, 1999), had the highest $I F_{2016}$. However, this single-author article was cited once in 2001 and 2011, respectively with $T C_{2016}$ of 2 and $C_{2016}$ of 0 . Brunei also published articles in other high impact journals, for example Nature $\left(I F_{2016}=40.137\right)$, Science $\left(I F_{2016}=37.205\right)$, BMJ-British Medical Journal $\left(I F_{2016}=20.785\right)$, Gastroenterology $\left(I F_{2016}=18.392\right)$, and Cell Metabolism $\left(I F_{2016}=18.164\right)$.

The number of journals per Web of Science category (Fig. 3) indicate that ecology dominated, with 153 journals publishing the most Brunei articles (8.0\% of 1257 articles), followed by multidisciplinary geosciences $(6.5 \%)$, inorganic and nuclear chemistry (5.3 $\%$ ), environmental sciences (5.0\%), electrical and electronic engineering (4.3\%), and mathematics $(4.2 \%)$. Brunei also focused on inorganic and nuclear chemistry with $5.3 \%$ of 1257 articles (only 46 journals are listed in the category).

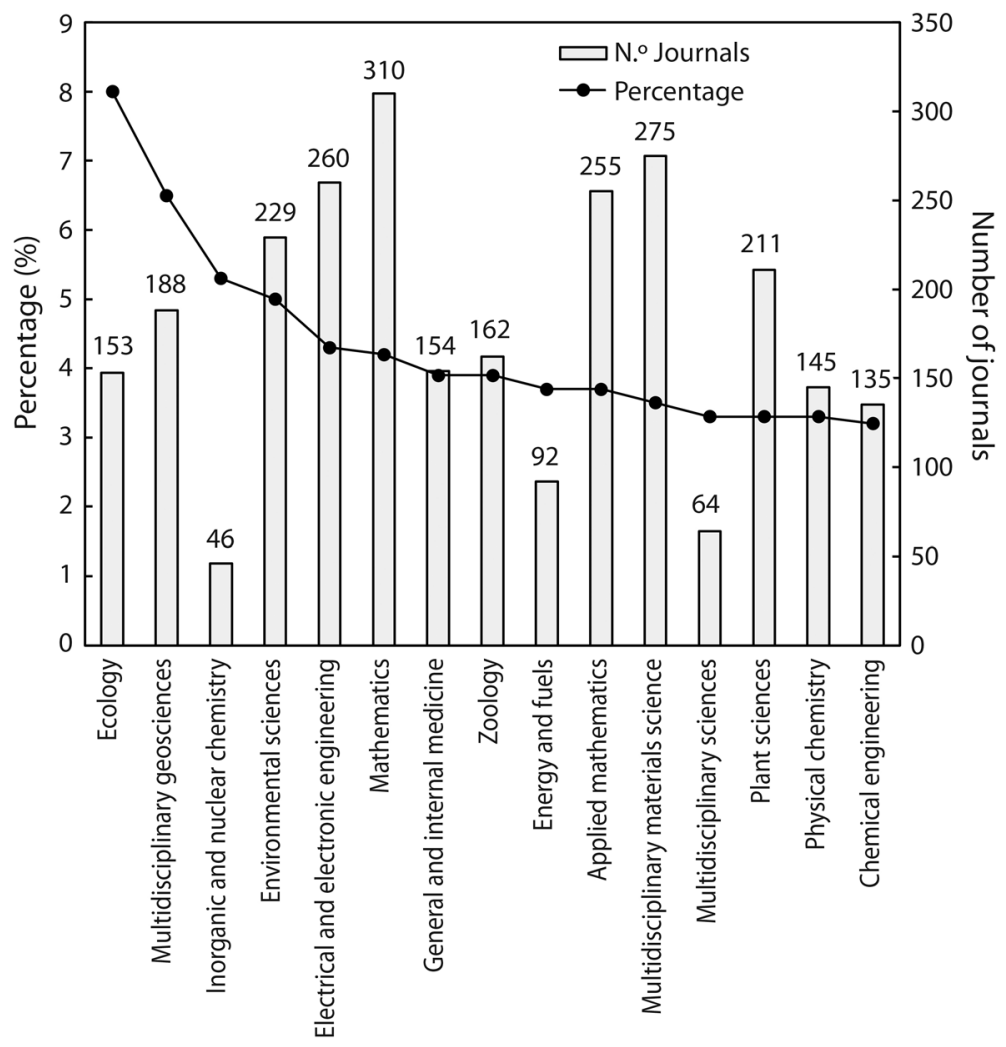

Fig. 3. Percentage of publications and number of journals in each Web of Science category. 
Highly cited articles: The number of highly cited publications has been used as indicator for ranking universities (Waltman et al., 2012), and top universities publish more classic articles (Ho \& Hartley, 2016). Regarding the top 10 Brunei articles which have received more than 100 citations (Table 4), seven were published after 2000. Only four had a first-author (including two single-authored articles) from Brunei and three had corresponding-author (including two single-authored articles) from Brunei. Highly cited single-author articles were published by C.K. Morley from the Department of Petroleum Geoscience in the Universiti Brunei Darussalam with $T C_{2016}$ of 208 (rank 4th) and $C_{2016}$ of 25 (rank 7th) and S. Mohamad from the Department of Mathematics in the Universiti Brunei Darussalam with $T C_{2016}$ of 155 (rank 6th) and $C_{2016}$ of 3 (rank 267th).

TABLE 4

Top ten articles with $T C_{2016}>100$

\begin{tabular}{|c|c|c|c|c|}
\hline $\begin{array}{c}\text { Rank } \\
\left(T C_{2016}\right)\end{array}$ & $\begin{array}{l}\text { Rank } \\
\left(C_{2016}\right)\end{array}$ & Article title & Country & Reference \\
\hline $1(328)$ & $5(28)$ & $\begin{array}{l}\text { Explaining the abundance of ants in lowland } \\
\text { tropical rainforest canopies }\end{array}$ & USA, Brunei & $\begin{array}{l}\text { Davidson et al. } \\
\qquad(2003)\end{array}$ \\
\hline $2(291)$ & $18(14)$ & $\begin{array}{l}\text { Fault geometries in basement-induced wrench } \\
\text { faulting under different initial stress states }\end{array}$ & Oman, Netherlands, Brunei & $\begin{array}{l}\text { Naylor et al. } \\
\text { (1986) }\end{array}$ \\
\hline $3(274)$ & $3(32)$ & $\begin{array}{l}\text { Levothyroxine treatment in euthyroid } \\
\text { pregnant women with autoimmune thyroid } \\
\text { disease: Effects on obstetrical complications }\end{array}$ & Italy, Brunei & $\begin{array}{l}\text { Negro et al. } \\
\quad(2006)\end{array}$ \\
\hline $4(208)$ & $7(25)$ & $\begin{array}{l}\text { A tectonic model for the Tertiary evolution of } \\
\text { strike-slip faults and rift basins in SE Asia }\end{array}$ & Brunei & $\begin{array}{l}\text { Morley } \\
(2002)\end{array}$ \\
\hline $5(156)$ & $133(4)$ & $\begin{array}{l}\text { The preparation, characterization, } \\
\text { crystal structure and biological activities } \\
\text { of some copper(II) complexes of the } \\
\text { 2-benzoylpyridine Schiff bases of } \\
\text { S-methyl- and S-benzyldithiocarbazate }\end{array}$ & Brunei, Bangladesh, Canada & $\begin{array}{l}\text { Hossain et al. } \\
\qquad(1996)\end{array}$ \\
\hline $6(155)$ & $196(3)$ & $\begin{array}{l}\text { Global exponential stability in continuous- } \\
\text { time and discrete-time delayed bidirectional } \\
\text { neural networks }\end{array}$ & Brunei & $\begin{array}{l}\text { Mohamad } \\
\text { (2001) }\end{array}$ \\
\hline $7(141)$ & $34(11)$ & $\begin{array}{l}\text { Biological activity of palladium(II) } \\
\text { and platinum(II) complexes of the } \\
\text { acetone Schiff bases of S-methyl- and } \\
\text { S-benzyldithiocarbazate and the X-ray crystal } \\
\text { structure of the [Pd(asme)(2)] (asme=anionic } \\
\text { form of the acetone Schiff base of } \\
\text { S-methyldithiocarbazate) complex }\end{array}$ & Brunei, USA, Malaysia & $\begin{array}{l}\text { Ali et al. } \\
(2002)\end{array}$ \\
\hline $8(123)$ & $16(15)$ & $\begin{array}{l}\text { The influence of selenium supplementation } \\
\text { on postpartum thyroid status in pregnant } \\
\text { women with thyroid peroxidase } \\
\text { autoantibodies }\end{array}$ & Italy, Brunei & $\begin{array}{l}\text { Negro et al. } \\
\quad(2007)\end{array}$ \\
\hline $9(120)$ & $2(36)$ & $\begin{array}{l}\text { Height-diameter allometry of tropical } \\
\text { forest trees }\end{array}$ & $\begin{array}{l}\text { UK, Brazil, Ghana, } \\
\text { Netherlands, Bolivia, USA, } \\
\text { France, Canada, Japan, } \\
\text { Brunei, Malaysia, Australia, } \\
\text { Colombia, Cameroon, Gabon }\end{array}$ & $\begin{array}{l}\text { Feldpausch et al. } \\
\qquad(2011)\end{array}$ \\
\hline $10(106)$ & $90(6)$ & $\begin{array}{l}\text { Vegetational history of a site in the central } \\
\text { Amazon basin derived from phytolith and } \\
\text { charcoal records from natural soils }\end{array}$ & Panama, Brunei & $\begin{array}{c}\text { Piperno and Becker } \\
\text { (1996) }\end{array}$ \\
\hline
\end{tabular}


A Brunei independent article entitled "A tectonic model for the Tertiary evolution of strike-slip faults and rift basins in SE Asia" (Morley, 2002) ranked top in both $T C_{2016}$ and $C_{2016}$. The earliest highly cited article was published in 1986 in collaboration with Oman and Netherlands with $T C_{2016}$ of 291 (rank 2nd) and $C_{2016}$ of 14 (rank 18th) and the most recent one in 2012 was collaboration with the UK with $T C_{2016}$ of 120 (rank 9th) and $C_{2016}$ of 36 (rank 2nd). Number of total citations for a publication is widely considered to be an indicator for highly cited publications. However, the highly cited articles are not always in top citations (Ho, 2014). Impact in the most recent year, $C_{2016}$, was also compared for the high impact publications (Ho, 2012). Only four highly cited articles ranked top ten in both $T C_{2016}$ and $C_{2016}$ including articles published by Davidson, Cook, Snelling, and Chua (2003), Negro et al. (2006), Morley (2002), and Feldpausch et al. (2011). In addition, three of the 10 highly cited articles were published in the Web of Science category of multidisciplinary geosciences: Naylor et al. (1986), Feldpausch et al. (2011), and Piperno and Becker (1996).

\section{DISCUSSION}

The dominance of article, over letters, notes, proceedings and other types of scientific documents, found in Brunei's publications, has also been found in most tropical countries studied this far (Monge-Nájera \& Ho, 2012, 2017c). The reason seems to be that articles are the basic unit of scientific work because they present a particular problem and its solution according to the scientific method, while letters and other documents do not include all the necessary aspects of detailed methods, full results and thorough analysis.

The fact that Brunei articles are $100 \%$ in English, while those of Latin American countries are often in Spanish, may reflect the fact that Spanish has a greater scientific output than Malay, the main language of Brunei; but a second possibility is that Brunei articles in Malay appear in journals that are not included in the Science Citation Index Expanded; similar results were reported previously for tropical countries (Monge-Nájera \& Ho, 2012, 2015, 2017a, 2017b, 2017c).

The recent increase in the number of publications seems to be a general trend of tropical countries, both in Asia (Payumo \& Sutton, 2015) and elsewhere (Monge-Nájera \& Ho, 2017c).

Internationally collaborative articles (IC) from Brunei received more citations per publication, $C P P_{2016}$, than institutional independent articles (II), and were followed by nationally collaborative articles $(N C)$. This result is in agreement with other tropical countries, for example Nicaragua (Monge-Nájera \& Ho, 2017a), Honduras (Monge-Nájera \& Ho, 2017b), and El Salvador (Monge-Nájera \& Ho, 2017c). International collaborative efforts tend to produce a higher number of authors and frequently wider exposure, and thus, are more likely to have higher citation rates (Glänzel, 2001; Payumo \& Sutton, 2015). This matches our finding that articles with a first-author and/ or corresponding-author from other countries tend to receive higher $C P P_{2016}$ than those with a first-author and/or corresponding-author from Brunei. The same trend has also been observed in Southeast Asia (Payumo \& Sutton, 2015). Nicaragua (Monge-Nájera \& Ho, 2017a), Honduras (Monge-Nájera \& Ho, 2017b), and El Salvador (Monge-Nájera \& Ho, 2017c).

The UK and Malaysia were the most frequent research partners with Brunei. There were more collaborations with Malaysia but they had lower impact, similar to a report by Payumo and Sutton (2015). However, researchers in Brunei had higher impact than Nicaragua (Monge-Nájera \& Ho, 2017a), Honduras (Monge-Nájera \& Ho, 2017b), and El Salvador (Monge-Nájera \& Ho, 2017c), possibly because the scientific infrastructure is much more developed in Brunei (Payumo \& Sutton, 2015). The predominance of collaboration with neighbouring countries, and with former colonial powers, also matches what is known from the tropical countries of Central America (Monge-Nájera \& Ho, 2017c). 
Brunei publications were dominated by ecology, similar to Panama in Central America (Monge-Nájera \& Ho, 2015). However, other tropical countries, for example Costa Rica, published the most articles in biology (MongeNájera \& Ho, 2012), while public, environmental and occupational health dominated research in Nicaragua (Monge-Nájera \& Ho, 2017a), Honduras (Monge-Nájera \& Ho, 2017b), and El Salvador (Monge-Nájera \& Ho, 2017c).

In conclusion, the tropical countries of Central America and Asia studied thus far have a few similarities but also important differences, and they are highly heterogeneous in their scientific organization and productivity: no simple generalizations can be made for the scientific output of tropical nations.

\section{RESUMEN}

Publicaciones de Brunei en el Science Citation Index Expanded (1973-2016): Bibliometría y comparación con otros países tropicales. Brunei es un pequeño país tropical del sudeste asiático, sobre el cual no hay estudios bibliométricos. Aquí analizamos los artículos publicados por científicos de Brunei de 1973 a 2016 y comparamos los resultados con otros países tropicales. Examinamos los documentos del Science Citation Index Expanded en la colección principal del Web of Science. Hallamos 1547 publicaciones de Brunei con 11 tipos de documentos, donde las categorías más productivas fueron ecología, geociencias multidisciplinarias, química inorgánica y nuclear, y ciencias ambientales. Singapore Medical Journal publicó la mayoría, y las tres instituciones más productivas fueron: Universiti Brunei Darussalam, RIPAS Hospital y Universiti Teknologi Brunei. Reino Unido y Malasia fueron los países que más colaboraron con Brunei. M.A. Ali de la Universidad Brunei Darussalam fue el autor más prolífico. El mayor número total de citas, y el mayor número de citas en 2016, correspondieron a un artículo exclusivamente de Brunei, escrito por C. K. Morley de la Universiti Brunei Darussalam en 2002. Los países tropicales de América Central y Asia tienen algunas similitudes pero también diferencias importantes, siendo heterogéneos en su organización científica y productividad.

Palabras clave: cienciometría; productividad; colaboración científica; temas principales de estudio.

\section{REFERENCES}

Ali, M. A., Mirza, A. H., Butcher, R. J., Tarafder, M. T. H., Keat, T. B., \& Ali, A. M. (2002). Biological activity of palladium (II) and platinum (II) complexes of the acetone Schiff bases of S-methyl- and S-benzyldithiocarbazate and the X-ray crystal structure of the $\left[\mathrm{Pd}(\text { asme })_{2}\right]$ (asme=anionic form of the acetone Schiff base of S-methyldithiocarbazate) complex. Journal of Inorganic Biochemistry, 92(3-4), 141-148.

Berkhout, A. J. (1973), Minimum phase criterion of sampled signals. IEEE Transactions on Geoscience and Remote Sensing, 11(4), 186-198.

Bhangu, A., Fitzgerald, J. E. F., Ademuyiwa, A. O., Recinos, G., Khatri, C., Glasbey, J. C., ... Raya, M. A. (2016). Mortality of emergency abdominal surgery in high-, middle- and low-income countries. British Journal of Surgery, 103(8), 971-988.

Chuang, K. Y., \& Ho, Y. S. (2015). An evaluation based on highly cited publications in Taiwan. Current Science, 108(5), 933-941.

Chuang, K. Y., Olaiya, M. U., \& Ho, Y. S. (2012). Bibliometric analysis of the Polish Journal of Environmental Studies (2000-11). Polish Journal of Environmental Studies, 21(5), 1175-1183.

Chuang, K. Y., Wang, M. H., \& Ho, Y. S. (2011). Highimpact papers presented in the subject category of water resources in the Essential Science Indicators database of the Institute for Scientific Information. Scientometrics, 87(3), 551-562.

Costas, R., \& Bordons, M. (2011). Do age and professional rank influence the order of authorship in scientific publications? Some evidence from a micro-level perspective. Scientometrics, 88(1), 145-161.

Davidson, D. W., Cook, S. C., Snelling, R. R., \& Chua, T. H. (2003). Explaining the abundance of ants in low and tropical rainforest canopies. Science, 300(5621), 969-972.

Elango, B., \& Ho, Y. S. (2017). A bibliometric analysis of highly cited papers from India in Science Citation Index Expanded. Current Science, 112(8), 1653-1658.

Feldpausch, T. R., Banin, L., Phillips, O. L., Baker, T. R., Lewis, S. L. Quesada, C. A., \& Lloyd, J. (2011). Height-diameter allometry of tropical forest trees. Biogeosciences, 8(5), 1081-1106.

Fu, H. Z., Wang, M. H., \& Ho, Y. S. (2012). The most frequently cited adsorption research articles in the Science Citation Index (Expanded). Journal of Colloid and Interface Science, 379(1), 148-156.

Glänzel, W. (2001). National characteristics in international scientific co-authorship relations. Scientometrics, 51(1), 69-115.

Ho, Y. S. (2012). Top-cited articles in chemical engineering in Science Citation Index Expanded: A bibliometric analysis. Chinese Journal of Chemical Engineering, 20(3), 478-488. 
Ho, Y. S. (2014). Classic articles on social work field in Social Science Citation Index: A bibliometric analysis. Scientometrics, 98(1), 137-155.

Ho, Y. S., \& Hartley, J. (2016), Classic articles published by American scientists (1900-2014): A bibliometric analysis. Current Science, 111(7), 1156-1165.

Ho, H. C., \& Ho, Y. S. (2015). Publications in dance field in Arts \& Humanities Citation Index: A bibliometric analysis. Scientometrics, 105(2), 1031-1040.

Ho, Y. S., Satoh, H., \& Lin, S. Y. (2010). Japanese lung cancer research trends and performance in Science Citation Index. Internal Medicine, 49(20), 2219-2228

Hossain, M. E., Alam, M. N., Begum, J., Ali, M. A., Nazimuddin, M., Smith, F. E., \& Hynes, R. C. (1996). The preparation, characterization, crystal structure and biological activities of some copper (II) complexes of the 2-benzoylpyridine Schiff bases of S-methyl- and S-benzyldithiocarbazate. Inorganica Chimica Acta, 249(2), 207-213.

Hsieh, W. H., Chiu, W. T., Lee, Y. S., \& Ho, Y. S. (2004) Bibliometric analysis of patent ductus arteriosus treatments. Scientometrics, 60(2), 205-215.

Mohamad, S. (2001). Global exponential stability in continuous-time and discrete-time delayed bidirectional neural networks. Physica D, 159(3-4), 233-251.

Monge-Nájera, J., \& Ho, Y. S. (2012), Costa Rica publications in the Science Citation Index Expanded: A bibliometric analysis for 1981-2010. Revista de Biología Tropical, 60(4), 1649-1661.

Monge-Nájera, J., \& Ho, Y. S. (2015). Bibliometry of Panama publications in the Science Citation Index Expanded: Publication type, language, fields, authors and institutions. Revista de Biología Tropical, 63(4), $1255-1266$.

Monge-Nájera, J., \& Ho, Y. S. (2017a). Bibliometrics of Nicaraguan publications in the Science Citation Index Expanded. Revista de Biología Tropical, 65(2), 643-655.

Monge-Nájera, J., \& Ho, Y. S. (2017b). Bibliometrics of Honduras publications in the Science Citation Index Expanded. Revista de Biología Tropical, 65(2), 657-658.

Monge-Nájera, J., \& Ho, Y. S. (2017c). El Salvador publications in the Science Citation Index Expanded: subjects, authorship, collaboration and citation patterns. Revista de Biología Tropical, 65(4), 1428-1436.

Morley, C. K. (2002). A tectonic model for the Tertiary evolution of strike-slip faults and rift basins in SE Asia. Tectonophysics, 347(4), 189-215.

Naylor, M. A., Mandl, G., \& Sijpesteijn, C. H. K. (1986), Fault geometries in basement-induced wrench faulting under different initial stress states. Journal of Structural Geology, 8(7), 737-752.

Negro, R., Formoso, G., Mangieri, T., Pezzarossa, A., Dazzi, D., \& Hassan, H. (2006). Levothyroxine treatment in euthyroid pregnant women with autoimmune thyroid disease: Effects on obstetrical complications. Journal of Clinical Endocrinology \& Metabolism, 91(7), 2587-2591.

Negro, R., Greco, G., Mangieri, T., Pezzarossa, A., Dazzi, D., \& Hassan, H. (2007). The influence of selenium supplementation on postpartum thyroid status in pregnant women with thyroid peroxidase autoantibodies. Journal of Clinical Endocrinology \& Metabolism, 92(4), 1263-1268.

Payumo, J. G., \& Sutton, T. C. (2015). A bibliometric assessment of ASEAN collaboration in plant biotechnology. Scientometrics, 103(3), 1043-1059.

Piperno, D. R., \& Becker, P. (1996). Vegetational history of a site in the central Amazon basin derived from phytolith and charcoal records from natural soils. Quaternary Research, 45(2), 202-209.

Riesenberg, D., \& Lundberg, G. D. (1990). The order of authorship: Who's on first? JAMA-Journal of the American Medical Association, 264(14), 1857.

Smit, W. J. F. (1999). Hyperkalaemia in a Thai man. Lancet, 354(9185), 1182-1182.

Stearn, J. E. F., \& Piper, J. D. A. (1984), Paleomagnetism of the sveconorwegian mobile belt of the fennoscandian shield. Precambrian Research, 23(3-4), 201-246.

Tchuifon Tchuifon, D. R., Fu, H. Z., \& Ho, Y. S. (2017). Cameroon publications in the Science Citation Index Expanded: Bibliometric analysis. Revista de Biología Tropical, 65(4), 1582-1591.

Waltman, L., Calero-Medina, C., Kosten, J., Noyons, E. C. M., Tijssen, R. J. W., van Eck, N. J., ... Wouters, P. (2012). The Leiden ranking 2011/2012: Data collection, indicators, and interpretation. Journal of the American Society for Information Science and Technology, 63(12), 2419-2432.

Wang, M. H., \& Ho, Y. S. (2011). Research articles and publication trends in environmental sciences from 1998 to 2009. Archives of Environmental Science, $5,1-10$.

Wang, M. H., Fu, H. Z., \& Ho, Y. S. (2011). Comparison of universities' scientific performance using bibliometric indicators. Malaysian Journal of Library \& Information Science, 16(2), 1-19.

Warren, J. (2000). Dolomite: Occurrence, evolution and economically important associations. Earth-Science Reviews, 52(1-3), 1-81. 